RESUMOS DE TRABALHOS

E/OU

RESUMOS COMENTADOS 


\section{MÃE-CRECHE: RELAÇOES AMBIVALENTES UM ESTUDO DE CASOS SOBRE A REPRESENTAÇAO DE USUÁRIAS*}

A tese tem como objetivo a procura de esclarecimentos e aprofundamento sobre o pensar e o sentir da mulher, na condição de mãe e de trabalhadora, diante da instituição creche, sob o ponto de vista de suas relações de uso. Ela é fruto de uma pesquisa exploratória, baseada em estudo de caso, em que o conceito de representação foi utilizado como instrumento para a compreensão e a análise interpretativa dos depoimentos .

O estudo a respeito da dupla condiçãomaternidade e trabalho, no sujeito mulher-propicia uma aproximação da essencia da realidade relacionas. A objetividade da categoria objeto de pesquisa está explicitada no aspecto fenomenológico do mundo mal, e expressa uma condição muito especifica do cotidiano da mulher na atual conjuntura.

A análise interpretativa indicou que as relações do sujeito mulher são ambivalentes em razão de um conflito, originado por ocasião da decisão de uso da creche, 0 qual recrudesce na vivência das relações com a instituição. O conflito se insere, inicialmente, na relação maternidade-trabalho, e, a seguir, na relação mãe riança; a tese prioriza 0 trato desta relação, denominada maternagem entendida como um estágio do processo de crescimento e de desenvolvimento do ser humano).
Maria Apparecida Motta ${ }^{1}$

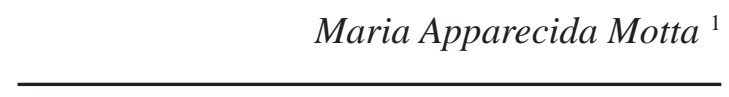
quisa. Assim, a tese desvela o conflito instalado nas relações de uso da mulher trabalhadora e de uma instituição que a sociedade coloca à sua disposição; ressalta a importância do entendimento do fenómeno maternagem no processo da dependência à maturidade, assistido pela creche que, entretanto, não o assume; aponta a creche como instituição necessária na realidade urbana de nossos dias considerando-a, contudo, como uma instituição em busca de identidade; indica a maternagem compartilhada como uma visão compreensiva necessária, através da qual a creche assume a tarefa de acompanhar a mãe no recriar-se intelectual e afetivamente, levando-a a entender e a aceitar a irnportancia da maternidade, concomitantemente com a importância do desempenho de outros papéis não rãlacionados ao de ser mãe.

A importância da tese reside no seu caráter dialogal, colocado à disposição da comunidade académica, dos interessados na problemática e da sociedade; sua proposta fundamental é uma nova abordagem de compreensão para o fenómeno da maternagern, tanto quanto para o complexo sistema que a envolve.

Tese de doutorado em Serviço Social, apresentada à Pon^l:if;cia Universidade Católica-SP, em 27 de Setembro de 1989.

1 Doutora em Serviço Social pela Pontifícia Universidade Católica-SP, docente da UniSantos e assessora técnica do Fundo Social de Solidariedade do Estado de São Paulo - FUSSESP. 


\section{O DESENVOLVIMENTO INFANTIL E SUAS REPRESENTAÇÕES: DIMENSÕES DO SABER TÉCNICO-PROFISSIONAL E DO SENSO-COMUM*}

O presente trabalho versa sobre as representações sociais de mães e de profissionais de saúde sobre o processo de desenvolvimento infantil. O estudo das representações foi realizado por meio da análise de discursos, coletados em 54 entrevistas realizadas com mulheres usuárias de duas unidades básicas de saúde, localizadas ha Grande São Paulo; e de 25 entrevistas efetuadas com profissionais de formação variada, participando, nessas unidades, em programações dirigidas à criança.

A análise do material coletado foi Letrada buscando caracterizar um "sistema articulado de unidades de sentido" em torno da questão "desenvolvimento infantil”. Esse sistema foi constituído através de três "núcleos estruturadores dos discursos" para cada grupo estudado, e ainda por categorias gerais e especificas de discurso e grupos temáticos.

As unidades de discurso, assim identificadas e caracterizadas, possibilitaram a discussão de algumas das relações estabelecidas com o processo de desenvolvimento infantil e práticas institucionais dirigidas à criança.

\author{
Denize Cristina de Oliveira ${ }^{1}$
}

As formas de estruturação do grupo familiar, os valores incorporados pela familia e transmitidos aos filhos através do processo de socialização das crianças, a própria socialização, como elemento importante no processo de crescimento e desenvolvimento, foram alguns dos temas discutidos a partir da análise das entrevistas de mães.No que se refere às práticas profissionais, foi destacada a temática das relações de poder estabelecidas entre mulheres usuárias dos serviços e o grupo profissional a eles vinculados. Essas relações foram analisadas a partir dos referênciais teóricos de "campo social" e de "violência simbólica”.

Como questão básica, as condições de produção do saber e das práticas daí derivadas perpassam o trabalho como um todo. Espera-se, com isso, contribuir para o processo de entendimento da dinamica das relações estabelecidas entre os níveis de saber envolvidos nas práticas institucionais da Saúde Pública - o saber do senso-comum por um lado, o saber técnico-profissional, por outro, além do conhecimento científico especializado do Setor.

\footnotetext{
Monografia de mestrado em Saúde Materoo-Infantil, apresentada à Faculdade de Saúde Pública da USP em 1991.

1 Técnico especializado em Ensino e Pesquisa do Departamento de Saúde Materno-Infantil da 1. Técnico especializado em Ensino e Pesquisa do Departamento de Saúde MaternoInfantil da Faculdade de Saúde Pública da USP.
} 


\section{O MEDICAMENTO COMO PROBLEMA DE SAÚDE PÚBLICA. CONTRIBUIÇÃO PARA O ESTUDO DE UMA MERCADORIA SIMBÓLICA*}

Fernando Lefèvre ${ }^{1}$

Na perspectiva da Saúde Pública e da Educação em Saúde Pública, através de uma pesquisa de geração de hipóteses, buscou-se analisar o sentido do medicamento, em nosso país, no momento presente.

Tendo como amparo teórico-filosófico geal a dialética e como amparo instrumental-analítico a semiótica, considerouse o medicamento de três pontos de vista: do ponto de vista do social, do ponto de vista do indivíduo e do ponto de vista do médico, considerados como instâncias capazes de atribuir sentido ao medicamento.

Do ponto de vista do social, considerou-se que a saúde está sujeita hoje, em nosso país, a um processo de reificação/simbolização e que 0 medicamento pode ser considerado, no bojo deste processo, como uma mercadoria simbólica.

Do ponto de vista dos indivíduos (representados pelos pacientes hipertensos), considerados ao mesmo tempo como objetos de um esforço social de inculcação ideológica e como sujeitos produtores autónomos de sentido, pode-se dizer que o medicamento aparece, associado a uma ampla temática correlata, como símbolo ambíguo, que remete ao mesmo tempo à Saúde e à Doença.

O ponto de vista do médico (o terceiro grande agente atribuidor de sentido ao medicamento) foi analisado sob a rubrica: relações simbolicas mantidas com o medicamento pelo prescritor médico.

Como conclusão do trabalho foram levantadas seis hipóteses relativas ao sentido do medicamento para os indivíduos.
Seria possível, evidentemente, levantar hipóteses sobre o sentido do medicamento para o social e para o médico.

Optou-se pelo individuo considerando que, tradicionalmente, a Educação em Saúde Pública é vista como prática de intervenção sobre individuos e grupos, sem desconsiderar o falo de que os comportamentos destes individuos e grupos são determinados, em última instancia, em nível macrossocial.

As hipóteses dizem respeito aos seguintes temas: artificial;

- O medicamento e a oposição: natural x cação;

- O medicamento e a relação de comuni-

- O medicamento como símbolo ambíguo de saúde e doença;

- O medicamento e a moral: obediência e transgressão; autonomia e heteronomia;

- O medicamento e o desejo: eficiência e eficácia simbó fica;

- O medicamento e a relação de consumo.

As hipóteses relativas a estes seis temas podem ser-consideradas pontos de partida para trabalhos posteriores, em que se buscará verificar, em populações especificas, a veracidade e a pertinência das afirmações nelas contidas.

Pretende-se que o presente trabalho dê lugar à criação de uma linha de pesquisa em Educação em Saúde Pública, que tenha como núcleo a produção do sentido da Saúde na sociedade brasileira contemporânea.

\footnotetext{
* Tese de doutorado em Educação em Saúde Pública.

1 Professor-doutor do Departamento de Prática em Saúde Pública da Faculdade de Saúde Pública da USP.
} 


\section{TEXTOS SELECIONADOS: DA PEDIATRIA À PSICANÁLISE}

WINNICOTT, D. W. Textos Seleciona los: da Pediatria à Psicanálise. Série Psicologia e Psicanálise. Tradução de Jane Russo; coordenação e revisão técnica de Sérvulo Augusto Figueira; revisão da terminologia médica de Érika M. Worobjow Almeida. $2^{\wedge}$ a ed., Rio de Janeiro, Francisco Alves, 1982, 526 p., ilustrado.

\section{CREDENCIAIS DAAUTORIA}

D. W. Winnicott, F. R. C. P., nasceu na Inglaterra, filho caçula de uma fanu1ia abastada de classe média; seu pai, Sir Frederick Winnicott, foi prefeito de Plimouth; foi médico do Paddington Green Children's Hospital e do Departamento Infantil da London Clinic of Psycho-Analisis, ambos em Londres - Inglaterra; presidiu a Divisão Médica da British Psycological Society. E considerado, por M. Masud R. Khan, como um dos quatro analistas (os outros três são Melanie Klein, Heinz Hartmann e Erik Erikson) que contribuíram com conceitos inteiramente novos, para ampliar o quadro clássico conceitual psicanalítico. Sua produção científica é riquíssima; de seus livros, foram traduzidos para o português, além da obra enfocada, os seguintes: A Criança e o seu Mundo e $O$ Brincar e a Realidade.

\section{CONCLUSOES DAAUTORIA}

Por se tratar de uma coletanea, Winnicott apresenta suas conclusões em forma de sumário, sobre cada um dos temas abordados, após cada texto. A obra oferece, no campo do conhecimento teórico-prático, uma valiosa colaboração, muito bem condensada no alentado prefácio de $\mathrm{M}$. Masud R. Khan, qu organizou os temas, como segue:

- Realidade interna versas fantasia, onde conclui que o indivíduo chega à realidade exter- na através das fantasias onipotentes elaboradas no esforço de fugir da realidade interna; explica que a "realidade interna" pressupõe a existência de um interior e de um exterior, e, portanto, de uma membrana Imitadora pertencente ao que posteriormente foi denominado o "psique-soma".

- Do objeto transicional ao uso do objeto, em que demonstra a importância do objeto transicional, não por ser uma coisa, sua condição de coisa é vital porque ajuda a criança a manter uma crescente e evolutiva realidade interna, bem como a estabelecer a diferença com o mundo do “não-self”. Em termos de psicanálise, descreve a relação objetal como experiência do sujeito. Demonstra que o analista e o paciente fazem parte de um processo total mais amplo no setting clínico (setting significando a soma de todos os detalhes do manejo), no qual cada um está sendo "criado" e "descoberto" pelo outro. E esta mutualidade e reciprocidade que cria um novo dinamismo dialogal, que é mais do que mera relação objetal na transferência.

- Regressão, manejo e jogo no setting clínico. Considera inadequado o uso do termo "regressão", sempre que um comportamento típico de bebe aparece na história de um caso. A palavra "regressão" manifesto uma representação popular, que o autor prefere não adorar; ao se falar de regressão em psicanálise, supõe-se a existência de uma organização da maneira pela qual o individuo armazena memórias, idéias e potencialidades. Existe sempre a expectativa do surgimento de condições favoráveis, que justificam uma vol-

1 Doutora em Serviço Social pela Pontiffcia Universidade Católica-SP, docente da UniSantos e assessora técnica do Fundo Social de Solidariedade do Estado de São Paulo - FUSSESP. 
ta e oferecem nova chance de desenvolvimento progressivo impossibilitado ou dificultado no inicio pelo fracasso ambiental. Denomina de "preocupação materna primária” a sensibilidade da mãe normal, que consegue sentir-se no lugar do bebe, e deste modo responder às suas necessidades; estas, inicialmente, são corporais e gradualmente tornam-se necessidades do ego, na medida em que, a partir da elaboração imaginativa da experiência física, surge a psicologia; portanto, a construção inicial do ego é silenciosa. Aponta a distinção dos conceitos de "brincar" (play) e "o brincar" (playing). Afirma que "o brincar (playing) é tão evidente nas análises dos adultos, quanto no casa do trabalho com crianças. Conclui que, em relação à teoria psica nalítica, quando há um ego intacto no paciente, o analista pod deixar de se preocupar com os detalhes mais antigos do cuidada materno, pois há esperança de que o selo verdadeiro possa ser ca paz de assumir os riscos que o início da experiência de viver im plica. Ressalta que a tendência anti-social não é um diagnóstica não se comparando com outros termos diagnósticos, tais com neurose e psicose; explícita que, quando há uma tendência anti social, houve uma verdadeira privação (não uma privação sim pies), isto é, houve a perda de algo bom que havia sido positiva na experiência da criança até uma determinada data, e que lhe fc retirado. Esta tendência é delineada pelo autor sempre em dua direções, apesar de, às vezes, a ênfase recair sobre uma ou outra roubo e destrutividade.

Em Classification: is there a psychoanalytic contribution to psychiatric classification?, publicado em 1959, Winnicott oferece uma das suas grandes contribuições, concluíndo que "os desejo reprimidos se prestam demais a processos simbolicos, enquanto que a privação das necessidades busca efetivação antes de o pro cesso simbolico poder começar a agir”. E resume o problema d; classificação ao afirmar que, no inicio do processo de desenvol vimento emocional de qualquer indivíduo, três coisas existem:; hereditariedade, o ambiente que sustenta ou falha e traumatiza, no meio está o indivíduo, que vive, que se defende e que cresce Sob o enfoque da psicanálise, é estudado o indivíduo, que vive que se defende e que cresce. No tocante à classificação, é abor dada a fenomenologia total, e o melhor modo de fazê-lo é classi ficar, primeiro, os estados ambientais; em seguida, classificar aí defesas do individuo; e, por fim, procurar olhar para a heredita riedade. De modo geral, a hereditariedade é a tendência inerente do individuo para crescer, integrar-se, relacionar-se com objetos amadurecer.
- A estruturação e a formacão de urna pessoa. Para Winnicott o paradoxo da relação mãefilho reside no falo de que o am biente (mãe) torna possível o self em formação do bebe. Evidencia, como analista, que uma mãe cuida carinhosamente do sei bebe, o frui e o cria: não só no interior somático do seu útero mas também nos primeiros estágios da descoberta e da percepçãc que Ihe foi dado de forma inata, e da pessoa em que ele, com c tempo, se diferenciará e se e^^fetivará; portanto, a essência da ex periência infantil reside na sua dependência do cuidado materno (ambiental). "O potencial herdado de um bebe sé pode vir a ser um bebe, se ligado à maternàgem", afirmou o autor; nesta etapa, o processo de maternagem é o holding, que se baseia mais na empatia materna que na compreensão.

Conforme conceituação do próprio Winnicott, o self - que não é o ego - é a pessoa que eu sou, que é somente eu, que possui uma totalidade baseada na operação do processo maturativo; o selo é constituído de partes que se aglutinam, num sentido interior-exterior, no curso da operação do processo maturativo, auxiliado pelo ambiente humano que o contém, que cuida dele, e de forma ativa, facilita-o. O sela central é o potencial herdado, que experimenta uma continuidade de ser e que está adquirindo, a sua moda e seu ritmo, uma realidade psíquica e um esquema corporal pessoais. O conceito de isolamento deste sela central é estudado, pelo autor, como característica de saúde; qualquer ameaça a este isolamento constitui uma ansiedade de grande importancia, e as defesas da mais tenra infancia surgem em relação aos fracassos por parte da mãe ou na maternagem.

- A solidão e a preocupação na localização da experiência cultural. O autor desenvolve o conceito de "fenómenos transicionais" da infancia, para incluir "o espaço potencial” da vida adulta na cultura. Este conceito emergiu de sua pesquisa gradual sobre os primeiros provimentos do ambiente materno, mostrando que estão vinculados ao uso criativo, que o adulto faz do que Ihe é dado em termos de cultura.

\section{DIGESTO}

A obra, publicada originalmente em Londres, Inglaterra, em 1958, sob o título Collected Papers, reunia diversas e variadas contribuições de Winnicott, destinadas a um público especializado. Em 1982, foi reeditada, incluindo uma introdução de M. Masud R. Khan, com o acréscimo de textos do autor, publicados posteriormente à primeira edição. 
O livro oferece um panorama da trajetória profissional percorrida pelo autor, em Pediatria e Psicanálise, com reconhecimento comprovado de psicanalistas, psicólogos, assistentes sociais e educadores, todos aqueles cuja prática envolva o cuidado com a criança, a educação e a saúde.

No prefácio, Khan apresenta Winnicott como um )uzppening: psique e soma em perpétuo diálogo e debate? homem e terapeuta como seres recir $\wedge$ Jrocos e harmoniosos; relatado trabalho do autor no Paddington Green Children's Hospital como clínico, e na British Psychological Society, como pesquisados.

O livro tem por objetivo mostrar que a Pediatria é também um caminho legítimo que leva à Psicanálise; trata-se de uma coletanea de trabalhos do autor, apresentados em três seções distintas, sob ordem cronológica, o que caracteriza o livro como obra, na qual Winnicott relata a evolução de sua teoria sobre a relação mãe-filho. De acordo com sua afirmação, o autor nunca se desligou da prática pediátrica, que foi seu ponto de partida.

Na primeira parte da obra estão incluidos dois capítulos de seu livro Clinical Notes on Discorders of Childhood, publicado em 1931 e já esgotado, onde está representada a sua atitude como pediatra, antes de sua formação psicanalística (notas sobre normalidade-ansiedade e agitação). Nesta parte, o autor enriquece o trabalho apresentando estudos de casos clínicos: aponta e comenta os sintomas físicos da ansiedade, e das mudanças físicas devido a causas emocionais; Ilustra as sugestões acerca dos mecanismos que trabalharam para a produção de algumas desordens psíquicas, um de cada vez (o olho, o nariz e a garganta); aborda as questões das causas físicas do nervosismo e da ansiedade, mascarando doenças físicas. O texto sobre agitação abrange três tipos comumente encontrados na prática clínica: agitação por excitação ansiosa, tiques e coréia, com ilustração de estudos de casos (anamnese, exame e prosseguimento). Bastante importante é a informação de que a febre reumática e a coréia tornaram-se bem menos comuns, desde a época em que o texto foi escrito; a incidência de irrequietação ansiosa comum e de tiques não se alterou.

A segunda parte da obra é constituída por trabalhos, que rã latam a pediatria sob a Ética da orientação psicanalítica. Trata-se de um conjunto de oito temas, apresentados desde 0 ano de 1936 até 1955, onde Winnicott relata seus casos, inclusive com ilustrações, descrição de técnicas utilizadas e comentários à luz da teoria psicanalítica; enfatiza a importância do cantata direto com crianças pe- quenas, como oportunidade rica para observação e terapia, e para a aplicação de princípios apreendidos através da análise de crianças e adultos.

Pessoalmente, atribuo muita importância ao texto "A Observação de Bebês em uma Situação Estabelecida", no qual é apresentado o estudo do caso de um bebe de sete meses, acometido por asma; a questão apresentou considerável interesse para a mó dicina psicossomático, visto que-na situação estabelecida - a criança em observação fornece importantes pistas acerca do estado do seu desenvolvimento emocional.

Bastante interesse contém o texto sobre “Apetite e Perturbação Emocional”, onde o cuidadoso registro da história de cada caso afetou o ponto de vista de Winnicott, clarificando a continuidade clínica das perturbacões do apetite, na forma como se apresentam nos primeiros periodos da mais tenra infancia, na infância propriamente dita, na adolescência e na vida adulta.

A terceira parte é constituída pela contribuição pessoal de Winnicott à teoria e à prática correntes na psicanálise. Dezesseis textos, escritos de 1935 a 1956, onde o autor tenta focalizar a atenção em um único processo, o do contato do individuo com a realidade partilhada e o desenvolvimento disto desde o inicio da vida do bebê. $\mathrm{O}$ autor centra sua intencionalidade em dois tipos de abordagem: a física e a psicológica tentando assimilar a contribuição de cada uma delas.

Winnicott apresenta em sua obra o conceito do objeto, do fenómeno e do espaço transicionais. A noção do objeto transicional é relativamente clara para a compreensão, pois adveio de pesquisa clínica que se estendeu por um período de quatro décadas e de contato com cerca de 60.000 bebes, crianças, mães, pais, com o casal, parentes e com avós. A pesquisa realizou-se com maior intensidade no Paddington Green Children's Hospital e no Queen’s Hospital for Children, em Londres, Inglaterra.

O texto "Observação de Bebês em uma Situacão Estabelecida”, já citado, contém as primeiras declarações de Winnicott sobre esta área de sua pesquisa, baseada nos estudos de observação do que ele chama de "uma espécie de intimidade”. No prefácio de Therapeutic Consultation in Child Psychiatry, descreve a relação em que mãe e filho vivem juntos uma experiência. Relata o emprego de uma espátula, na técnica que denominou "o jogo da espátula”, e no qual se destaca o momento de ilusão do qual parte para consolidar os conceitos de objeto transicional e de fenómenos transicionais. 


\section{METODOLOGIA DAAUTORIA}

O autor utiliza o método indutivo, recorrendo aos procedi nentos analíticos e interpretativos da Pediatria e da Psicanálise. Suas pesquisas baseiasn-se na obra de Freud, através de duas hipóteses:

- Sobre a estrutura da mente em termos de Ego, Id e Superego (1923); e

- Revisão da teoria da ansiedade (1926).

O desenvolvimento de suas pesquisas demonstram sua proposta fenomenológica; adota procedimentos metodológicos como a analogia e técnicas como a monográfica com estudos de caso e histórias de vida.

\section{CRITICA DA RESENHISTA}

A leitura apresenta-se objetivamente descritiva; a obra revela o pesquisador a procura de sua verdade, valendo-se de sua vivência profissional; seu integral aproveitamento supõe conhecimento prévio da teoria psicanalítica e constitui- rá valioso instrumento para os estudiosos do mundo infantil.

A obra apresenta dois aspectos importantes a serem considerados: é uma coletanea sistematizada de textos do autor, procurando mostrar a gênesee de sua teoria; trata-se de uma tradução, e como tal, apresenta dificuldades no entendimento de termos estrangeiros.

A grande contribuição de Winnicott, além de mostrar a operacionalização dos cuidados pediátricos sob a ática psicanalítica, consiste em ressaltar a importancia da proteção da mãe e seu bebe; nada deve interferir no vinculo entre ambos, que é a essência e a própria natureza do cuidado materno.

\section{INDICAÇÕES DA RESENHISTA}

Esta obra apresenta especial interesse para estudantes e pesquisadores de Educação, Saúde, Psicologia e Serviço Social. Poderá ser utilizada para cursos de pós-graduação, como modelo de proposta de trabalho, tendo em vista sua metodologia. 